\title{
Qualidade nutricional das proteínas de cupuaçu e de cacau
}

\author{
Nutritional quality of cupuassu and cocoa proteins
}

\author{
Alessandra Santos LOPES ${ }^{1 *}$, Nelson Horacio PEZOA-GARCÍA², Jaime AMAYA-FARFÁN
}

\section{Resumo}

O cupuaçu desponta como um importante produto agrícola de exportação com ampla perspectiva de mercado devido à aceitação que desfruta entre os consumidores regionais e de outros estados do país. O presente estudo teve como objetivo avaliar a qualidade protéica de produtos em pó formulados com amêndoas torradas de cupuaçu e cacau. De acordo com o ensaio biológico Net Protein Ratio, realizado a partir de dietas contendo $10 \%$ de proteína na proporção de cupuaçu ou cacau:caseína (50:50), verificou-se que as proteínas do cupuaçu apresentaram valor biológico significativamente superior $(\mathrm{p} \leq 0,05)$ ao das proteínas de cacau, promovendo aumento de peso dos animais $57,4 \%$ maior. No que se refere às necessidades diárias para crianças e adultos, o perfil aminoacídico das proteínas do cupuaçu teve desempenho superior ao das proteínas do cacau.

Palavras-chave: cupuaçu; cacau; proteína; aminoácido; valor biológico.

\begin{abstract}
Cupuassu has arisen as an important agricultural export product, with widespread market perspectives due to its acceptance amongst regional consumers and those in other Brazilian states. The objective of the present study was to evaluate the protein quality of powdered products formulated with roasted cupuassu and cocoa beans. According to the net protein ratio determined in biological trials using diets containing $10 \%$ protein in a 50:50 proportion of cupuassu or cocoa:casein, it was shown that cupuassu proteins presented a significantly superior ( $\mathrm{p} \leq 0.05$ ) biological value as compared to cocoa proteins, promoting a 57.4\% greater weight increase in the animals than cocoa proteins. With respect to the daily requirements of children and adults, the amino acid profile of cupuassu proteins presented a better performance than cocoa proteins.
\end{abstract}

Keywords: cupuassu; cocoa; protein; amino acid; biological value.

\section{Introdução}

O cupuaçuzeiro (Theobroma grandiflorum Schum) é uma das plantas frutíferas de maior importância para a Amazônia, principalmente devido a sua participação na composição dos sistemas de produção, cultivados e extrativos, além da grande aceitação e consumo da polpa de seus frutos (ROCHA NETO; FIGUERÊDO; SOUZA, 1997).

O cupuaçu desponta como um importante produto agrícola de exportação com amplas perspectivas de mercado, dadas à aceitação que desfruta entre os consumidores regionais e de outros estados. Além das características intrínsecas do fruto, o consumo de produtos provenientes da região Amazônica é um outro fator que vem propiciando o interesse de outros países pelo cupuaçu (BUENO, 1997; CALZAVARA, 1987; QUEIROZ, 1999; VENTURIERI, 1993) .

A similaridade das amêndoas de cupuaçu e cacau tem despertado interesse científico, pois a partir das sementes de cupuaçu fermentadas e torradas podem ser obtidos produtos análogos ao chocolate e achocolatados de excelente qualidade em termos de sabor (LOPES; PEZOA-GARCÍA; VASCONCELOS, 2003).
As sementes, resíduo do processo de extração da polpa de cupuaçu, ainda não são aproveitadas para formulação de alimentos industrializados, apesar de diversas pesquisas científicas já terem sido realizadas a fim de fornecer conhecimento tecnológico para implementação industrial desta matéria-prima.

Os produtos de cacau se enquadram entre os alimentos altamente energéticos e estimulantes, cujo sabor é uma característica muito importante. Além de estar intimamente relacionado à variedade e à origem, o sabor é influenciado pelo processamento, cujo desenvolvimento potencial deste depende principalmente dos processos de fermentação e torração (ZAK; KEENEY, 1976). Dentre as modificações que ocorrem durante a fermentação, pode-se ressaltar a hidrólise específica de proteínas, especialmente da fração globulina (VOIGT; BIEHL, 1993), proporcionando a formação de peptídeos e aminoácidos (MOHR; LANDSCHREIBER; SEVERIN, 1976; ROHAN; STEWART, 1967) e a hidrólise da sacarose em glicose e frutose (ROHAN, T. A.; STEWART, 1967). Os compostos formados na fermentação são os precursores do sabor de cacau desen-

Recebido para publicação em 8/6/2006

Aceito para publicação em 13/2/2008 (001688)

${ }^{1}$ Faculdade de Engenharia de Alimentos, Universidade Federal do Pará - UFPA. Rua Augusto Corrêa, 01, CP 479, CEP 66075-110, Belém - PA, Brasil, E-mail: aslopes@ufpa.br

2 Departamento de Tecnologia de Alimentos, Faculdade de Engenharia de Alimentos, Universidade Estadual de Campinas - UNICAMP, CP 6121, CEP 13083-970,

Campinas - SP, Brasil, E-mail: nelson@fea.unicamp.br

${ }^{3}$ Departamento de Planejamento Alimentar e Nutrição, Faculdade de Engenharia de Alimentos, Universidade Estadual de Campinas - UNICAMP, CP 6121, CEP 13083-970, Campinas - SP, Brasil, E-mail: jaf@fea.unicamp.br

${ }^{*}$ A quem a correspondência deve ser enviada 
volvido na torração através da reação de Maillard (FORSYTH; QUESNEL, 1957; PEZOA, 1989).

Meursing (1983) determinou o valor nutritivo de achocolatado em pó, assim como a digestibilidade de seus constituintes. Foram observados teores de lipídios entre 9 a 23\%, dependendo da formulação do produto, e a digestibilidade destes compostos atingiu $90 \%$. As proteínas $(19,8 \%)$ e os carboidratos $(37,9 \%)$ apresentaram valores de digestibilidade de 42 e 32\%, respectivamente.

Nos alimentos, as proteínas podem ser classificadas conforme a qualidade, que depende da proporção dos aminoácidos, da biodisponibilidade e da suscetibilidade à hidrólise durante a digestão. Da qualidade da proteína resulta o seu valor nutritivo. Em geral, as proteínas de origem animal são de maior valor nutritivo do que as proteínas de origem vegetal (BURTON, 1979; FARFÁN, 1994).

O cacau é um produto de grande importância na economia brasileira, e o cupuaçu um fruto com grandes potencialidades para a industrialização, por isso é importante avaliar o aspecto nutricional de ambas as espécies.

Este trabalho teve como objetivo avaliar a qualidade protéica dos pós de cupuaçu e de cacau desengordurados, através de ensaio biológico e da quantificação de aminoácidos totais, visando contribuir para o melhor aproveitamento das amêndoas de cupuaçu, através do desenvolvimento de novos produtos com aporte nutricional derivados do pó de cupuaçu.

\section{Material e métodos}

\subsection{Material}

Foram utilizadas amêndoas fermentadas de cupuaçu e de cacau provenientes da região de Tomé-Açu (PA).

\subsection{Torração}

Os processos de torração das amêndoas fermentadas de cupuaçu e de cacau foram realizados em torrador elétrico rotativo da marca PROBAT WERKE munido de controle de temperatura, com precisão de $\pm 0,1^{\circ} \mathrm{C}$. A temperatura de torração foi estabelecida em $150{ }^{\circ} \mathrm{C}$ para as amêndoas de cupuaçu e de cacau, no entanto, foram utilizados tempos de processamento de 55 minutos para o cupuaçu e 46 minutos para o cacau. Os binômios tempo/temperatura empregados no presente trabalho para as amêndoas de cupuaçu e de cacau foram obtidos de acordo com Lopes; Pezoa-García e Vasconcelos (2003), nos quais o parâmetro de definição utilizado foi a aceitação sensorial de produtos formulados com os liquors (cotilédone finamente moído) de cupuaçu e de cacau, utilizando-se diferentes tempos de torração.

\subsection{Processo de obtenção dos pós desengordurados}

As amêndoas de cupuaçu e de cacau torradas foram quebradas em moinho de facas tipo RIETZ, e as cascas separadas do cotilédone em coluna de ar. Os cotilédones foram refinados em moinho de rolos paralelos ajustáveis até granulometria de
$50 \mu \mathrm{m}$, e a extração da gordura foi realizada em equipamento similar ao extrator Soxhlet, utilizando como solvente o hexano. Após obtenção de teor de gordura inferior a $1 \%$, as amostras foram secas em estufa a vácuo, a $40{ }^{\circ} \mathrm{C}$ por 10 a 12 horas para eliminar qualquer resíduo de solvente.

\subsection{Preparo das dietas e ensaio biológico}

As dietas foram preparadas segundo a AIN-93G 19, com teor de proteína de 9,5 a 10,5\%, conforme Tabela 1 . Após o preparo, determinou-se o teor de proteína de cada dieta pelo método semi-micro Kjeldhal, com amostras em triplicata (AOAC, 1997). As metodologias empregadas para aplicação do teste de avaliação nutricional foram: o NPR (Quociente de Eficiência Líquida da Proteína) (Equação 1) e o RNPR (\%) (Quociente de Eficiência Líquida da Proteína Relativo a uma Proteína de Referência - caseína) (BENDER; DOELL, 1957; REEVES; NIELSEN; FAHEY, 1993).

Para a realização do ensaio biológico, foram preparadas: uma dieta com $10 \%$ de caseína como fonte única de proteína (padrão), uma dieta aprotéica, isto é, desprovida de proteína e 2 dietas com $5 \%$ da proteína correspondendo ao material de cacau ou de cupuaçu desengordurado e 5\% da caseína completando os 10\% necessários para a realização do ensaio biológico destes grupos (Tabela 1).

Foram selecionados $32(\mathrm{n}=8)$ ratos (linhagem Wistar) recém desmamados, que apresentavam pesos mais homogêneos por grupo em relação à média de peso global. $\mathrm{O}$ experimento teve duração de 16 dias, constituídos da fase de adaptação (2 dias) e o ensaio propriamente dito (14 dias). A temperatura do ambiente foi mantida em $22 \pm 2{ }^{\circ} \mathrm{C}$ e a iluminação dosada em ciclos de luz/escuro de 12 horas. O peso e o consumo alimentar dos animais foram registrados em intervalos de 2 dias durante o experimento (Equação 1).

NPR = ganho de peso G1 $(\mathrm{g})+$ média da perda de peso G2 $(\mathrm{g})$ proteína consumida

em que:

$\mathrm{G} 1$ = grupo em dieta protéica; e

G2 = grupo em dieta aprotéica.

\subsection{Aminoácidos totais}

Os aminoácidos totais foram extraídos através do procedimento de hidrólise dos pós desengordurados de cupuaçu e de cacau. As amostras obtidas foram filtradas em membrana Millipore (tamanho de poro de $0,22 \mu \mathrm{m}$ ) e estocadas sob temperatura de congelamento até a análise. As determinações foram feitas usando-se um cromatógrafo líquido de alta eficiência TSP - Thermo Separation Products, com bomba degaseificadora, acoplada a um módulo de pré-reação Pickering Laboratories PCX 3100 post column reaction module, operando com detector de UV, nas faixas de 440 a $570 \lambda$, modelo SPECTRO SYSTEM UV2000, operando com programa TSP 1000. Utilizou-se uma coluna analítica Pickering Laboratories $1193250\left(\mathrm{Na}^{+} 8 \mu \mathrm{m}\right.$, 
Tabela 1. Composição das dietas utilizadas no ensaio biológico (NPR).

\begin{tabular}{lcccc}
\hline \multicolumn{1}{c}{ Componentes } & Padrão (\%) & Aprotéica (\%) & Cupuaçu torrado (\%) & Cacau torrado (\%) \\
\hline Amido de milho & 47,29 & 59,75 & 34,37 & 34,46 \\
Pó desengordurado $^{\text {Caseína }}{ }^{1}$ & - & - & $19,15^{2}$ & $19,13^{2}$ \\
Maltodextrina $_{\text {Sacarose }}^{12,46}$ & - & 6,23 & 6,23 \\
Óleo de soja & 13,20 & 13,20 & 13,20 & 13,20 \\
Mistura mineral & 10,00 & 10,00 & 10,00 & 10,00 \\
Mistura vitamínica & 7,00 & 7,00 & 7,00 & 7,00 \\
Fibra & 3,50 & 3,50 & 3,50 & 3,50 \\
L-Cistina & 1,00 & 1,00 & 1,00 & 1,00 \\
Bitartarato de colina & 5,00 & 5,00 & 5,00 & 5,00 \\
Tertbutilhidroquinona & 0,30 & 0,30 & 0,30 & 0,30 \\
Teor de proteína (\%) & 0,25 & 0,25 & 0,25 & 0,25 \\
Ca & 0,0014 & 0,0014 & 0,0014 & 0,0014 \\
\end{tabular}

${ }^{1}$ Caseína comercial: $80,28 \%$ de proteína; ${ }^{2}$ as quantidades dos pós desengordurados de cupuaçu e de cacau forneciam $5 \mathrm{~g}$ de proteína em $100 \mathrm{~g}$ de dieta; $\mathrm{e}^{3} \mathrm{média} \pm$ desvio padrão (valores em base úmida).

$2 \mathrm{mmID} \times 250 \mathrm{~mm}$ ), acoplada a uma pré-coluna Pickering Laboratories $1192020\left(\mathrm{Na}^{+} 8 \mu \mathrm{m}, 2 \mathrm{mmID} \times 20 \mathrm{~mm}\right)$.

\subsection{Análise estatística}

Todas as análises físicas, químicas e físico-químicas foram realizadas em triplicata, e os valores obtidos foram avaliados com o auxílio do programa Statistica ${ }^{\circledR}$ versão 5.0 (STATSOFT, INC., 1995) empregando as seguintes metodologias estatísticas:

- Análise de variância (ANOVA) a 5\% de significância estatística segundo o teste $F$; e

- Teste de Tukey $(\mathrm{p} \leq 0,05)$.

\section{Resultados e discussão}

\subsection{Teor de proteína dos pós de cupuaçu e cacau}

Os pós de cacau e cupuaçu obtidos após extração de gordura não apresentaram mais que $1 \%$ de gordura, evitando a influência deste constituinte na avaliação protéica. Os teores de proteína dos pós desengordurados utilizados no preparo das dietas são mostrados na Tabela 2.

Bispo (1999) obteve teores de proteína entre 20,74 e 23,79\% nos pós de cacau alcalinizados e parcialmente desengordurados, isto é, com concentração de gordura de 13,05\%. No Brasil, o conteúdo de gordura presente no pó de cacau comercializado pode variar de 9 a $24 \%$, dependendo do fim a que se destina (BISPO, 1999; BRITO, 2000).

De acordo com Meursing (1983), a concentração de proteína em pó de cacau representa em média 19,8\% do peso total, além de apresentar baixo valor calórico, quando comparado a outros ingredientes usados conjuntamente com cacau em pó para formulação de produtos alimentícios.

\subsection{Ensaio biológico}

Durante o período de adaptação dos animais (2 dias), notou-se que a dieta formulada com pó de cacau causou redução nos pesos dos animais da ordem de $5,5 \%$, a qual se minimizou
Tabela 2. Teores médios de proteína dos pós desengordurados de cupuaçu e cacau.

\begin{tabular}{lcc}
\hline \multicolumn{1}{c}{ Pó desengordurado } & Umidade (\%) & Proteína (\%) ${ }^{1}$ \\
\hline $\begin{array}{l}\text { Cupuaçu torrado } \\
\text { (55 minutos) }\end{array}$ & $7,2 \pm 0,08$ & $28,14 \pm 0,26$ \\
$\begin{array}{l}\text { Cacau torrado } \\
(46 \text { minutos) }\end{array}$ & $8,6 \pm 0,10$ & $28,71 \pm 0,14$ \\
\hline
\end{tabular}

${ }^{1}$ Em base seca.

até o início do ensaio, o que é considerado comum na mudança de dieta. Para as dietas formuladas com pó de cupuaçu e para a dieta padrão foram observados ganhos de peso da ordem de 4,7 e 10,6\%, para este mesmo período de estudo (Tabela 3 e Figura 1). Em relação ao início do experimento propriamente dito, os pesos médios entre as quatro dietas avaliadas não apresentaram diferença estatística $(\mathrm{p}>0,05)$.

A partir do $2^{\circ}$ dia do experimento (Tabela 3 ) foi verificada diferença significativa estatisticamente $(p \leq 0,05)$ entre os pesos médios dos animais das dietas à base de cacau e caseína. No entanto, não houve diferença estatística $(p>0,05)$ entre as dietas de cupuaçu e caseína, assim como entre cupuaçu e cacau.

No $6^{\circ}$ dia do experimento (Tabela 3 ), observou-se diferença estatística significativa de $5 \%$ entre as dietas de cupuaçu e cacau, a qual permaneceu até o término do experimento. Neste mesmo período, verificou-se diferença significativa $(\mathrm{p} \leq 0,05)$ entre as dietas padrão (caseína) e cupuaçu.

Ao final do experimento (14 dias) as dietas padrão, pó de cupuaçu e pó de cacau (Tabela 3 ) apresentaram diferença $(\mathrm{p} \leq 0,05)$, e o cupuaçu em pó desengordurado promoveu aumento no peso dos animais $57,4 \%$ maior que o pó desengordurado de cacau. Isto revela a potencialidade nutricional do cupuaçu quando comparado ao cacau.

Drummond (1998) relatou que embora a proteína do cacau contenha grande variedade de aminoácidos e a proteína bruta represente mais ou menos $25 \%$ nos sólidos do cacau em pó desengordurado, o cacau não é uma fonte importante de proteínas. Todavia, mesmo com essas indicações um pouco desfavoráveis, as proteínas do cacau não podem ser desprezadas, 
particularmente quando são comparadas com outros alimentos de origem vegetal.

Abecia Soria (1999) reportou que a contribuição biológica das proteínas de cacau é de 37 a 38\%, contribuição pequena se comparada com a do leite, que é de $84 \%$. Do total das proteínas do cacau, $38 \%$ são digeríveis, $37 \%$ são usadas para manutenção e $14 \%$ são usadas dieteticamente, comparando-se respectivamente com $95,82,5$ e $80 \%$ das proteínas do leite.

$\mathrm{Na}$ medida em que os produtos achocolatados participam em quantidades variáveis da alimentação normal, especialmente da população infantil, o uso do cupuaçu como substituto do cacau poderia contribuir positivamente para o estado nutricional desses consumidores.

Durante o ensaio biológico observou-se que as fezes dos animais que consumiram as dietas de cacau em pó desengordurado tinham coloração marrom escura, foram excretadas em maior número e possuíam tamanho inferior àquelas oriundas dos animais que consumiram as dietas de cupuaçu em pó desengordurado ou caseína. Drummond (1998) verificou ocorrência

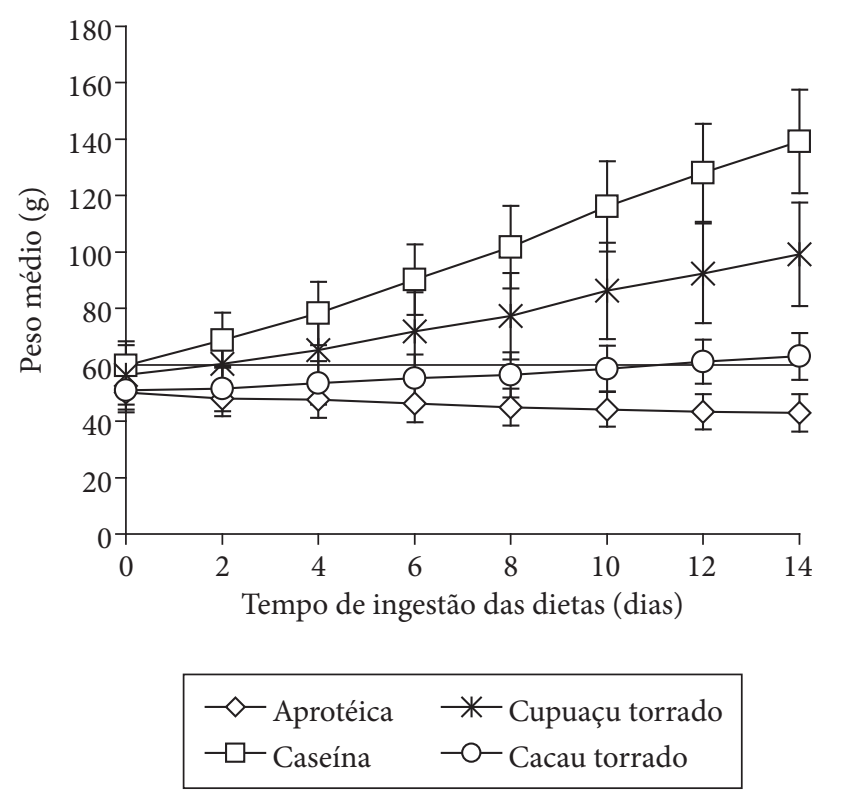

Figura 1. Variação de peso dos animais durante ensaio biológico. análoga ao ministrar liquor de cacau em dietas para ratos da linhagem Wistar.

Na Tabela 4 são apresentados os valores de NPR e RNPR(\%). Foi observado que a dieta formulada com pó desengordurado de cupuaçu apresentou valor de NPR cerca de 47,78\% maior que a dieta preparada com cacau. Apesar dos valores de NPR e RNPR (\%) encontrados para a dieta de cacau serem estatisticamente inferiores $(\mathrm{p} \leq 0,05)$ aos da dieta formulada com cupuaçu, verificou-se que as proteínas de cacau apresentaram valor biológico suficiente para garantir a manutenção do peso dos animais.

De acordo com Jansen (1978), o NPR do isolado protéico de soja é $2,71 \pm 0,12$. Tendo em conta que os valores de NPR encontrados para as dietas à base de cupuaçu foram semelhantes ao NPR do isolado protéico de soja, podemos constatar que o valor biológico das proteínas do cupuaçu pode ser considerado bom.

\subsection{Aminoácidos totais}

Na Tabela 5 são apresentados os teores de aminoácidos totais encontrados nos pós desengordurados de cupuaçu e de cacau. O cupuaçu apresentou para os aminoácidos essenciais isoleucina, leucina, metionina, cisteína, tirosina, treonina e valina, teores mais elevados que o cacau, exceto para a lisina, histidina e fenilalanina. $\mathrm{O}$ teor de lisina do pó desengordurado de cupuaçu (46 mg. $\mathrm{g}^{-1}$ proteína) foi menor que o valor encontrado para o pó de cacau (54 $\mathrm{mg}^{-g^{-1}}$ proteína), considerando o padrão protéico teórico $\left(51 \mathrm{mg} \cdot \mathrm{g}^{-1}\right.$ proteína $)$.

Quando um ou mais aminoácidos aparecem na proteína em quantidades inferiores às requeridas pelo organismo receptor ou em relação a um padrão de referência, tais aminoácidos são tidos como limitantes. $\mathrm{O}$ aminoácido limitante afeta o

Tabela 4. Valores de NPR e RNPR (\%).

\begin{tabular}{lcc}
\hline \multicolumn{1}{c}{ Dietas } & NPR & RNPR (\%) \\
\hline Caseína (padrão) & $4,47 \pm 0,18^{\mathrm{a}}$ & $100^{\mathrm{a}}$ \\
Cacau torrado & $2,03 \pm 0,19^{\mathrm{b}}$ & $45,41^{\mathrm{b}}$ \\
Cupuaçu torrado & $3,00 \pm 0,20^{\mathrm{a}}$ & $67,11^{\mathrm{c}}$ \\
\hline
\end{tabular}

${ }^{1}$ Médias com expoentes diferentes em uma mesma coluna indicam diferença estatística $(\mathrm{p} \leq 0,05)$.

Tabela 3. Média dos pesos dos grupos de animais $(\mathrm{n}=8)$ alimentados com as dietas de caseína, aprotéica, pó de cupuaçu torrado e pó de cacau torrado.

\begin{tabular}{|c|c|c|c|c|c|c|c|c|c|}
\hline \multirow[t]{3}{*}{ Dieta } & \multicolumn{9}{|c|}{ Evolução dos pesos médios dos animais ${ }^{1}$} \\
\hline & \multicolumn{9}{|c|}{ Tempo (dias) } \\
\hline & $(-2)^{2}$ & 0 & 2 & 4 & 6 & 8 & 10 & 12 & 14 \\
\hline Caseína & $\begin{array}{r}54,04^{\mathrm{a}} \\
(8,60)\end{array}$ & $\begin{array}{l}59,76^{\mathrm{a}} \\
(8,51)\end{array}$ & $\begin{array}{l}68,68^{\mathrm{a}} \\
(9,72)\end{array}$ & $\begin{array}{r}78,25^{\mathrm{a}} \\
(11,20)\end{array}$ & $\begin{array}{r}90,18^{\mathrm{a}} \\
(12,54)\end{array}$ & $\begin{array}{l}101,76^{\mathrm{a}} \\
(14,68)\end{array}$ & $\begin{array}{l}116,18^{a} \\
(16,04)\end{array}$ & $\begin{array}{l}128,00^{\mathrm{a}} \\
(17,37)\end{array}$ & $\begin{array}{l}139,26^{\mathrm{a}} \\
(18,32)\end{array}$ \\
\hline $\begin{array}{l}\text { Cupuaçu } \\
\text { torrado }\end{array}$ & $\begin{array}{r}53,85^{\mathrm{a}} \\
(11,12)\end{array}$ & $\begin{array}{r}56,38^{\mathrm{a}} \\
(10,49)\end{array}$ & $\begin{array}{c}60,25^{\mathrm{ab}} \\
(11,13)\end{array}$ & $\begin{array}{c}65,28^{\mathrm{ab}} \\
(12,28)\end{array}$ & $\begin{array}{r}71,85^{\mathrm{b}} \\
(13,89)\end{array}$ & $\begin{array}{r}77,24^{\mathrm{b}} \\
(15,33)\end{array}$ & $\begin{array}{r}86,25^{\mathrm{b}} \\
(17,12)\end{array}$ & $\begin{array}{r}92,43^{\mathrm{b}} \\
(17,67)\end{array}$ & $\begin{array}{r}99,13^{\mathrm{b}} \\
(18,34)\end{array}$ \\
\hline Aprotéica & $\begin{array}{l}54,67^{\mathrm{a}} \\
(8,25)\end{array}$ & $\begin{array}{l}50,15^{\mathrm{a}} \\
(6,05)\end{array}$ & $\begin{array}{l}48,10^{\mathrm{b}} \\
(6,27)\end{array}$ & $\begin{array}{l}47,65^{c} \\
(6,45)\end{array}$ & $\begin{array}{l}46,25^{c} \\
(6,65)\end{array}$ & $\begin{array}{l}45,00^{c} \\
(6,53)\end{array}$ & $\begin{array}{l}44,20^{c} \\
(6,15)\end{array}$ & $\begin{array}{l}43,39^{c} \\
(6,28)\end{array}$ & $\begin{array}{l}42,91^{\mathrm{d}} \\
(6,63)\end{array}$ \\
\hline
\end{tabular}

${ }^{1}$ Médias com expoentes diferentes em uma mesma coluna indicam diferença estatística ( $\left.\mathrm{p} \leq 0,05\right)$; ${ }^{2}$ período de adaptação ( 2 dias); e Valores entre parênteses = desvio padrão. 
Tabela 5. Teor de aminoácidos totais dos pós desengordurados de cupuaçu e cacau, padrão teórico e requerimento para crianças e adultos.

\begin{tabular}{lcc}
\hline Aminoácido & $\begin{array}{c}\text { Cupuaçu } \\
\left(\mathrm{mg} \cdot \mathrm{g}^{-1} \text { proteína }\right)\end{array}$ & $\begin{array}{c}\mathrm{Cacau}^{2} \\
\left(\mathrm{mg}^{-1} \mathrm{~g}^{-1} \text { proteína }\right)\end{array}$ \\
\hline Aspártico & $121 \pm 4$ & $89 \pm 4$ \\
Treonina & $53 \pm 2$ & $36 \pm 2$ \\
Serina & $54 \pm 2$ & $42 \pm 2$ \\
Glutâmico & $125 \pm 4$ & $158 \pm 8$ \\
Prolina & $38 \pm 1$ & $35 \pm 2$ \\
Glicina & $44 \pm 2$ & $37 \pm 2$ \\
Alanina & $40 \pm 1$ & $42 \pm 2$ \\
Cisteína & $19 \pm 1$ & $12 \pm 3$ \\
Valina & $56 \pm 2$ & $51 \pm 2$ \\
Metionina & $16 \pm 1$ & $11 \pm 3$ \\
Isoleucina & $43 \pm 1$ & $35 \pm 3$ \\
Leucina & $70 \pm 2$ & $53 \pm 3$ \\
Tirosina & $36 \pm 1$ & $30 \pm 1$ \\
Fenilalanina & $37 \pm 1$ & $38 \pm 2$ \\
Lisina & $46 \pm 3$ & $54 \pm 2$ \\
Histidina & $14 \pm 0$ & $14 \pm 1$ \\
Arginina & $55 \pm 2$ & $69 \pm 3$ \\
\hline
\end{tabular}

Aminoácido essencial Padrão teórico Requerimento Requerimento

\begin{tabular}{|c|c|c|}
\hline $\begin{array}{c}(\mathrm{ANC})^{3} \\
\left(\mathrm{mg} \cdot \mathrm{g}^{-1}\right. \\
\text { proteína) }\end{array}$ & $\begin{array}{l}\text { crianças } \\
\text { (até } 1 \text { ano })^{4} \\
\left(\mathrm{mg} \cdot \mathrm{g}^{-1}\right. \\
\text { proteína) }\end{array}$ & $\begin{array}{c}\text { adultos } \\
\left(\mathrm{mg} \cdot \mathrm{g}^{-1}\right. \\
\text { proteína })^{4}\end{array}$ \\
\hline
\end{tabular}

\begin{tabular}{llll}
\hline Treonina & 35 & 43 & 9 \\
Metionina + cisteína & 26 & 42 & 17 \\
Valina & 48 & 55 & 13 \\
Isoleucina & 42 & 46 & 13 \\
Leucina & 70 & 93 & 19 \\
Fenilalanina + tirosina & 73 & 72 & 19 \\
Lisina & 51 & 66 & 16 \\
Histidina & 17 & 26 & 16 \\
Triptofano & 11 & 17 & 5 \\
\hline
\end{tabular}

Pó de cupuaçu desengordurado; ${ }^{2}$ pó de cacau desengordurado; ${ }^{3}$ padrão teórico de qualidade protéica dado pela Academia de Ciências da América do Norte (SGARBIERI, 1996); $\mathrm{e}^{4}$ Fonte: Henley e Kuster (1994).

valor nutritivo da proteína, diminuindo a capacidade do organismo sintetizar suas próprias proteínas nos tecidos e células (SGARBIERI, 1996).

$\mathrm{O}$ teor de histidina foi limitante tanto para o cupuaçu (14 mg. $\mathrm{g}^{-1}$ proteína) quanto para o cacau ( $14 \mathrm{mg} . \mathrm{g}^{-1}$ proteína), no entanto, este aminoácido é requerido em especial em recémnascidos, para os quais o valor desejado é de $33 \mathrm{mg} . \mathrm{kg}^{-1}$ peso corporal/dia, de acordo com Sgarbieri (1996) e Farfán (1994).

A destruição de alguns aminoácidos durante a hidrólise limita sua quantificação para avaliação do ponto de vista nutricional, pois alguns aminoácidos essenciais (cisteína, treonina e tirosina) são parcial ou totalmente (triptofano) destruídos. Segundo Abecia Soria (1999), a isoleucina, tirosina, histidina e triptofano são aminoácidos limitantes para as amêndoas de cacau.

Vasconcelos (1999) observou pequena redução no teor da maioria dos aminoácidos ao longo do processo fermentativo de amêndoas de cupuaçu; por outro lado, serina, glicina, metionina, fenilalanina e arginina apresentaram suave elevação. Já Brito (2000) afirma que apesar das intensas modificações ocorridas durante a fermentação de cacau, o teor de aminoácidos totais permanece praticamente inalterado durante a fermentação.

Como exemplo de algumas fontes de proteínas vegetais, $o$ trigo, o milho, o amendoim e o algodão, são particularmente limitantes em lisina, assim como observado no pó de cupuaçu desengordurado. Já o amendoim, o feijão, a soja, o algodão e os germens de trigo e de milho são deficientes em metionina. $\mathrm{O}$ consumo de misturas de feijão e arroz ilustra o efeito da complementação das proteínas quando se combinam os alimentos, pois o valor biológico da mistura é significativamente superior ao de qualquer um dos dois em separado. Enquanto o feijão é rico em lisina e pobre em metionina, o arroz é rico em metionina, mas pobre em lisina (SGARBIERI, 1996).

\section{Conclusões}

As proteínas do cupuaçu apresentaram considerável potencial nutricional, pois possuem valor biológico e composição aminoacídica superiores às do cacau.

\section{Agradecimentos}

Os autores agradecem à CAPES pela bolsa de estudo concedida ao primeiro autor.

\section{Referências bibliográficas}

ABECIA SORIA, L. A. Estudo do valor nutritivo e da fração albumina dos extratos de proteína solúvel de amêndoas de cacau (Theobroma cacao L.) em função do grau de torração. Campinas, 1999. 127p. Dissertação (Mestrado em Tecnologia de Alimentos) Faculdade de Engenharia de Alimentos, UNICAMP.

AOAC. Association Official Analytical Chemists. Official Methods of Analysis. 16 ed. Gaithersburg: Patricia Cunniff (Ed.), 1997.

BENDER, A. E.; DOELL, B. H. Note on the determination of net protein utilization by carcass analysis. British Journal of Nutrition, Cambridge, v. 11, p. 138-143, 1957.

BISPO, E. S. Processo de alcalinização dos “nibs” de cacau (Theobroma cacao L.) e avaliação da qualidade do pó. Campinas, 1999. 198p. Tese (Doutorado em Tecnologia de Alimentos) Faculdade de Engenharia de Alimentos, UNICAMP.

BRITO, E. S. Estudo das mudanças estruturais e químicas produzidas durante a fermentação, secagem e torração do cacau (Theobroma cacao L.); e propostas de tratamentos para o melhoramento do sabor. Campinas, 2000. 167p. Tese (Doutorado em Tecnologia de Alimentos) - Faculdade de Engenharia de Alimentos, UNICAMP.

BUENO, N. Alguns aspectos recentes da nutrição do cupuaçuzeiro. In: Seminário Internacional Sobre Pimenta-do-Reino e Cupuaçu. 1997, Belém. Anais... Belém: Embrapa Amazônia Oriental, 1997. 440p.

BURTON, B. T. Nutrição humana. São Paulo: McGraw-Hill do Brasil, 1979. p. 49-66. Cap. 7.

CAlZAVARA, B. B. G. Cupuaçuzeiro. Recomendações Básicas 1. Belém: EMBRAPA/CPATU, 1987.

DRUMMOND, M. C. M. Relação entre o grau de torração do cacau (Theobroma cacao L.), sua qualidade nutricional e atributos sensoriais. Campinas, 1998. 127p. Dissertação (Mestrado em 
Tecnologia de Alimentos) - Faculdade de Engenharia de Alimentos, UNICAMP.

FARFÁN, J. A. Química de proteínas aplicada à ciência e tecnologia dos alimentos. 2. ed. Campinas: Editora da UNICAMP, 1994. $134 \mathrm{p}$.

FORSYTH, W. G. C.; QUESNEL, V. C. Cacao glycosidase and colour changes during fermentation. Journal of the Science of Food and Agriculture, London, v. 8, p. 505-509, 1957.

HENLEY, E. C.; KUSTER, J. M. Protein quality evaluation by protein digestibility-corrected amino acid scoring. Food Technology, Chicago, v. 48, n. 4, p. 74-77, 1994.

JANSEN, G. R. Biological evaluation of protein quality. Food Technology, Chicago, v. 32, n. 12, 1978.

LOPES, A. S.; PEZOA-GARCÍA, N. H.; VASCONCELOS, M. A. M. Avaliação das condições de torração após a fermentação de amêndoas de cupuaçu (Theobroma grandiflorum Schum) e cacau (Theobroma cacao L.). Brazilian Journal of Food Technology, Campinas, v. 6, n. 2, p. 309-316, 2003.

MEURSING, E. H. Cocoa powders for industrial processing : applications, quality characteristics, specifications, methods of analysis, miscellaneous data and tables. 3 . ed. The Netherlands Cocoa Fabriek, Dezaen B.V, 126 p.

MOHR, W.; LANDSCHREIBER, E.; SEVERIN, T. On the specificity of cocoa aroma. Fette Seifen Anstrichmittel, Alemanha, v. 78, n. 2, p. 88-95, 1976.

PEZOA, G. N. H. Contribution a l'étude d'un capteur por controler en continu le procédé de torréfaction. Compiègne, France, 1989. 170 p. Tese (Doutorado em Tecnologia de Alimentos). Université de Technologie de Compiègne.

QUEIROZ, M. B. Estudo dos parâmetros de torração de amêndoas de cupuaçu (Theobroma grandiflorum). Campinas, 1999. 109 p. Dissertação (Mestrado em Tecnologia de Alimentos) - Faculdade de Engenharia de Alimentos, UNICAMP.
REEVES, P. G.; NIELSEN, F. H.; FAHEY, G. C. J. AIN-93 Purified Diets for Laboratory Rodents: Final Report of the American Institute of Nutrition Ad Hoc Writing Committee on the Reformulation of the AIN-76A Rodent Diet. The Journal of Nutrition, Philadelphia, v. 123, n. 11, p. 1939-1951, 1993.

ROCHA NETO, O. G.; FIGUERÊDO, F. J. C.; SOUZA, N. G. Comportamento estomático e fotossintético de plantas jovens de cupuaçuzeiro (Theobroma grandiflorum Schum. In: Seminário Internacional sobre Pimenta-do-Reino e Cupuaçu. 1997, Belém. Anais... Belém: Embrapa Amazônia Oriental, 1997. 440 p.

ROHAN, T. A.; STEWART, T. The precursos of chocolate aroma: production of reducing sugars during fermentation of cocoa beans. Journal of Food Science, Chicago, v. 32, p. 399-402, 1967.

ROHAN, T. A.; STEWART, T. The precursos of chocolate aroma: production of free amino acids during fermentation of cocoa beans. Journal of Food Science, Chicago, v. 32, p. 395-398, 1967.

SGARBIERI, W. C. Proteínas em alimentos protéicos: propriedades, degradações, modificações. São Paulo: Livraria Varela, 1996.

STATSOFT, INC. STATISTICA for Windows. Computer program manual. Tulsa, OK: StatSoft, Inc., 1995.

VASCONCELOS, M. A. M. Transformações físicas e químicas durante a fermentação de amêndoas de cupuaçu (Theobroma grandiflorum Schum). Campinas, 1999. 114p. Dissertação (Mestrado em Tecnologia de Alimentos) - Faculdade de Engenharia de Alimentos, UNICAMP.

VENTURIERI, G. A. Cupuaçu: a espécie, sua cultura, usos, e processamento. Belém: Clube do Cupu, 1993. 108 p.

VOIGT, J.; BIEHL, B. The major seed proteins of Theobroma cacao L. Food Chemistry, Oxford, v. 47, p. 145-151, 1993.

ZAK, D. L.; KEENEY, P. G. Extraction and fractionation of cocoa proteins as applied to several varieties of cocoa beans. Journal of Agriculture and Food Chemistry, Washington, v. 24, n. 3, p. 479-486, 1976. 